\title{
Rutin mediated targeting of signaling machinery in cancer cells
}

\author{
Aliye Aras Perk', Iryna Shatynska-Mytsyk ${ }^{2}$, Yusuf Can Gerçek', Kadir Boztaş ${ }^{1}$, Mevzule Yazgan ${ }^{1}$, Sundas Fayyaz ${ }^{3}$ \\ and Ammad Ahmad Farooqi ${ }^{3}$
}

\begin{abstract}
Progress in our understanding of molecular oncology has started to shed light on dysregulation of spatio-temporally controlled signaling pathways, inactivation of tumor suppressor genes, tumour and normal stem cell quiescence, overexpression of oncogenes, extracellular and stromal microenvironments, epigenetics and autophagy. Sequentially and characteristically it has been shown that cancer cells acquire the ability to escape from apoptotic cell death, proliferate uncontrollably, sustain angiogenesis and tactfully reconstitute intracellular pathways to avoid immune surveillance. We have attempted to provide a recent snapshot of most recent progress with emphasis on how rutin modulates wide ranging intracellular signaling cascades as evidenced by in-vitro and in-vivo research. It is worth describing that 'single-cell proteomics' analysis has further improved our understanding regarding intracellular signaling pathways frequently activated in cancer cells resistant to therapeutics and can provide biomarkers for cancer diagnosis and prognosis. Data obtained from preclinical studies will prove to be helpful for scientists to bridge basic and translational studies.
\end{abstract}

Keywords: Signaling, Cancer, Apoptosis

\section{Introduction}

Decades of research have using high-throughput technologies have sequentially revealed that cancer is a multifaceted and genomically complex disease. Genetic, genomic and proteomic studies have provided near complete resolution of landscape of molecular oncology. It is now progressively becoming more clear that inactivation of tumor suppressor genes, overexpression of oncogenes, genomic instability, genetic/epigenetic mutations, tumor microenvironment, intracellular signaling cascades and loss of apoptosis are some of the extensively studied mechanisms. Death receptor pathway is a complicated biological mechanism that initiates by the binding of extracellular ligands such as FasL and TRAIL to respective transmembrane receptors [1]. Ligands signal through the receptors and trigger intracellularly assembly of death domain adaptor protein, FADD and procaspase-8 at receptor to form death inducing signaling complexes (DISC). Activated caspase-8 further activates caspase-3, which is an essential step of

\footnotetext{
* Correspondence: shatynskairene@yandex.ru

${ }^{2}$ Diagnostic Imaging and Radiation Therapy Department, Lviv National Medical University, Lviv, Ukraine

Full list of author information is available at the end of the article
}

extrinsic pathway. Intrinsic pathway operates through transmigration of Bid after caspase- 8 mediated cleavage into mitochondrion, thus facilitating release of cytochromec, SMAC/DIABLA, Omi/Htra. Mechanistically it has been shown that a signalosome is formed by assembly of Cytochrome C, APAF and Pro-caspase-9 to form a apoptosome. Activated caspase-9 further activated caspase-3 [2,3].

There is a list of newly emerging scientific evidence highlighting molecular mechanisms reported to be modulated by rutin to induce apoptosis in cancer cells. We partition this commentary into in-vitro and in-vivo evidences which have added new layers of knowledge into the existing pool of scientific information related to rutin.

\section{In vitro studies}

Rutin present in curry leaf Murraya koenigii extracts is an active ingredient and has significant activity against breast cancer MDA-MB-231 cells [4]. DNA protective effects of rutin against pro-carcinogens in HTC hepatic cells are also reported [5]. We divide this multi-component discussion into how rutin modulates, Wnt signaling, JAKSTAT signaling, EGF signaling, AP-1, NF-kB and Akt. We 
also discuss how ER stress induced response is targeted by rutin to induce apoptosis in cancer cells.

\section{Wnt signaling}

Binding of WNT protein to the receptor complex initiates a signaling cascade intracellularly. Negative modulators of beta-catenin including CK1 (casein kinase 1), GSK3beta, AXIN1 and APC are inhibited and $\beta$-catenin moves into the nucleus to form an active transcription factor complex with TCF to transcriptionally upregulate target genes [6,7].

Hammada scoparia flavonoidic fraction and its bioactive ingredient rutin exerted inhibitory effects on survival of leukemic progenitors (CD34(+)38(-)123(+)). Moreover, there was a notable decrease in active glycogen synthease kinase $3 \beta$ (GSK-3 $\beta)$ in rutin treated cells [8]. Wolfberry water soluble phytochemicals specifically rutin and quercetin have been shown to stabilize $\beta$-catenin in Jurkat cells. Detailed in-vitro analysis indicated an increase in $\beta$-catenin protein alongwith a dose-dependent decrease in phosphorylation of GSK-3 $\beta$ on Ser9 in Jurkat cells [9] Shown in figure. Although Rutin did not target Wnt/ $\beta$-catenin signaling in an experimental model of Xenopus embryos [10], it still needs research in different cancer cell lines.

Figure showing Wnt induced signaling. Rutin has been shown to target different modulators of Wnt signaling.

\section{JAK-STAT signaling}

It is now well established that cytokine-receptor-associated Janus-family kinases (JAKs) phosphorylate intracellularly located, cytoplasmic tails of the receptor to provide docking sites for positioning of monomeric STATs. These receptor docked STATs are phosphorylated and transported into the nucleus to trigger expression of target genes. Increasingly it is being realized that STAT3 mediated signaling is negatively modulated by different inhibitory molecules. Rutin has been shown to inhibit inflammatory responses in UVB-irradiated mouse skin by inhibiting the increase in phosphorylated levels of STAT3 [11].

Therapeutically controlling STAT3 signaling using different natural phytochemicals although has shown promise [12-14] however it still needs a detailed research.

\section{EGFR induced signaling}

Epidermal Growth Factor (EGF) induced signaling has emerged as a deeply studied molecular mechanism. It is intriguing to note that EGF signaling is frequently deregulated in different cancers [15-17]. EGF signals through EGFR in cancer cells. EGFR undergoes autophosphorylation at tyrosine residues and is reported to be involved in activating various downstream effectors of different signaling axis particularly, Ras/Raf/Mek/ Erk and PI3K/Akt. Rutin has been shown to inhibit EGFR kinase activity. Rutin also exerted inhibitory effects on Akt and Raf/MEK/ERK signaling pathways. Rutin has been noted to directly bind with EGFR as evidenced by pull-down assay which indicated that EGFR protein was pulled down with rutin-Sepharose 4B beads [18]. This finding needs additional verification in different cancer cell lines to know if Rutin can effectively inhibit EGFR induced signaling in HER2-overexpressing breast cancer. Moreover, how effectively rutin may inhibit PDGFR and VEGFR is also an outstanding question that needs to be addressed.

\section{AP-1, NF-KB and Akt}

Activator proteins (AP-1) include the JUN, FOS, ATF protein families, which undergo homo-dimerization and hetero- dimerization through their leucine-zipper domains [19]. AP-1activity has been reported to be modulated by extracellular signals including growth factors and intracellular signaling primarily through extracellularsignal-regulated kinase (ERK), p38 and c-Jun $\mathrm{N}$ terminal Kinase [20].

Inhibitor of -Kappa B (ІкB) bound Nuclear factor-Kappa B (NF-kB) exists in an inactive state in the cytoplasm, however, proteasomal degradation of IкB promotes its nuclear accumulation to trigger expression of antiapoptotic genes [21].

Transactivation of AP-1 and NF- $\mathrm{kB}$ was also notably reduced in rutin treated cells [18]. Wolfberry water soluble phytochemicals specifically rutin and quercetin have considerable biological activity against jurkat cells. Results revealed inhibition of $\mathrm{NFKB}$ and $\mathrm{AKT}$ activity in jurkat cells [9]. Rutin also inhibited inflammatory responses in UVB-irradiated mouse skin by inhibiting the increase in phosphorylated levels of p38 MAPK and JNK. Moreover, AP-1 did not show nuclear accumulation in rutin treated cells [11].

\section{Endoplasmic reticulum (ER) stress}

The endoplasmic reticulum (ER) stress triggers activation of multifunctional sensors including activating transcription factor 6 (ATF6), inositol-requiring protein 1 (IRE1) and PKR-like ER kinase (PERK) to transduce information about the folding status [22]. Signaling machinery consisting of IRE1 and PERK undergo oligomerization in the plane of the membrane and activated by trans-autophosphorylation of activation loop during ER stress [23]. Some other well studied triggers for ER stress response include loss of binding to BIP (chaperone immunoglobulin heavy chainbinding protein) and intricate interaction with misfolded proteins [23]. Mechanistically, rutin was reported to considerably reduce ROS, IRE1, PERK and ATF6 to induce apoptosis in cancer cells. Gene silencing strategy also confirmed that PERK, ATF6 and IRE1 silenced cancer cells displayed a higher apoptotic rate [9]. 


\section{Extrinsic and Intrinsic pathway}

BCL2/BAX ratio and expression of BCL2, both were notably reduced in rutin treated neuroblastoma LAN-5 cells. G2/M arrest and a marked increase in apoptotic rate were noted in neuroblastoma LAN-5 cells [24]. Rutin present in ethanolic extract of aerial parts of Pupalia lappacea also exerted effects on leukemia K562 cells by functionalizing intrinsic pathway mediated apoptosis [25]. Extract of Cyrtosperma johnstonii contains rutin as a bioactive ingredient and has potent biological activity against small cell lung carcinoma cells as evidenced by cell cycle arrest and apoptosis [26].

\section{In vivo}

Rutin considerably reduced tumor growth in mice xenografted with SW480 colon cancer cells [27]. Extract of Phyllanthus urinaria is rich in polyphenols particularly rutin. Extract has been shown to remarkably inhibit tumor spread in mice xenografted with metastatic A549 and Lewis lung carcinoma (LLC) cells. Mechanistically it was shown that nuclear accumulation of NF- $\mathrm{kB}$ and AP-1 was drastically reduced. Moreover, metalloproteinase2 expression was also noted to be downregulated [28]. It is noteworthy that administration of $120 \mathrm{mg} / \mathrm{kg}$ of rutin in mice xenografted with leukemia HL-60 cells induced regression of tumor [29]. Radioprotective effects of troxerutin are also studied in irradiated mice [30]. Extract of Prunella vulgaris is enriched in rosmarinic acid, quercetin and rutin. Extract significantly inhibited tumor growth in C57BL/6 mice [31]. It has previously been convincingly revealed that rutin remarkably reduced size of enlarged spleen in mice intraperitoneally injected with WEHI-3 cells [32]. Rutin has been shown experimentally to effectively block development of adenomas in the lungs of wild-type mice, however the results were not noted in BRM null mice [33]. It has recently been reported that preneoplasic lesions induced by 1,2-dimethylhydrazine in rat colon were remarkably reduced in troxerutin treated animal group [34].

There is a direct piece of experimental evidence suggesting that rutin mediated suppression in monocyte migration into peritoneal tumors contributes to tumor growth. The results revealed that macrophages infiltrating tumor dramatically reduced peritoneal colorectal carcinoma metastases however rutin significantly inhibited infiltration of macrophages [35].

\section{Human studies}

Pharmacokinetic profile of rutin was determined in 18 healthy non-obese females having normal cholesterol levels who volunteered for the study. Plasma flavonoids were considerably higher in the rutin-supplemented females. Endogenous oxidation of pyrimidines was significantly decreased in both placebo and rutin-treated volunteers
[36]. In another, diet-controlled, double blind two-period cross-over study, 16 healthy volunteers were orally administered with varying doses of rutin. After rutin ingestion, inter-individual variability in maximum concentration (Cmax) and area under curve (AUC) (0-32) values were significant and gender associated [37]. Mesenteric lymphatic/duodenum-cannulated rat model was intraduodenally administered with $300 \mathrm{mg} / \mathrm{kg}$ of Rutin. Maximum concentration of rutin in lymph, was slightly lesser as compared to plasma. Area under curve (AUC) of rutin in lymph was 2-fold higher as compared to plasma rutin [38].

\section{Pharmacokinetics}

There is a recent report suggesting that phenolic compounds including resveratrol, quercetin, and rutin displayed poor absorption through colon adenocarcinoma Caco-2 cells [39]. Different approaches have been utilized to enhance availability of rutin and in line with this approach, encapsulation of rutin in different substituents of cyclodextrin, such as 2-hydroxypropyl- $\beta$-cyclodextrin $(\mathrm{HP}-\beta-\mathrm{CD})$, hydroxypropyl- $\gamma$-cyclodextrin $(\mathrm{HP}-\gamma-\mathrm{CD}), \beta$-cyclodextrin $(\beta-C D)$ and $\gamma 2-\beta$-cyclodextrin $(\gamma 2-\beta-C y D)$ have shown potential in improving solubility and stability of rutin [40]. Mechanistically it has been shown that $\beta-C D$ and HP- $\beta-C D$ formed stable inclusion complexes with rutin [41]. Rutin dissolution rates enhanced efficiently upon complexation with cyclodextrins. Cyclodextrins stabilize rutin in gastrointestinal tract (GIT) after oral administration as rutin hydrolysis in small intestinal homogenates of drug treated animal group was considerably reduced. Oral bioavailability of rutin has also been noted to be significantly increased upon complexation with HP- $\beta-C y D$ as evidenced by faster dissolution rate, increase in solubility and gastrointestinal stability. Higher aqueous solubility and negligible toxicity is a hallmark of HP- $\beta-C y D$ associated pharmaceutical formulations.

Absorption of rutin from the gastrointestinal tract (GIT) is slower. Cross-linked sodium carboxy, methylcellulose (CMC-XL) has been used to formulate rutin containing fast-release tablets and prolonged-release formulations using hydroxypropylmethylcellulose (HPMC) of different viscosity grades have also been developed [42]. There is an exciting piece of evidence highlighting that hydrolyzed rutin had a higher biological activity against wide ranging cancer cell lines [43].

\section{Rutin regulation of DNA damage}

Ethyl methanesulfonate (EMS) induced alkylation mediated DNA damage was notably reduced in Drosophila melanogaster males because rosmarinic acid and rutin encircled nucleotides and occupied EMS binding space thus generating an impermeable barrier for the EMS molecule to trigger alkylation [44]. Moreover, Doxorubicin induced DNA damage was notably reduced in Rutin 
treated hepatoma HepG2 cells [45]. However, another role of Rutin has been documented as a DNA damage inducer. Rutin moderately induced DNA damage in BRCA mutant cells [46]. The data related to how Rutin actually modulates DNA damage signaling is insufficient and needs detailed research. It will be essential to note how it positively and/or negatively modulates DNA damage signaling in different cancer cell lines.

\section{Concluding remarks}

Although there are advancements in understanding of the molecular networks and signaling cascades reported to be modulated by rutin in cancer cells, it still needs detailed research. TGF/SMAD and SHH mediated signaling axis are insufficiently studied in different cancer cell lines. Moreover, we still have outstanding questions regarding rutin mediated effects on oncogenic and tumor suppressor micro RNAs. Detailed and extensive research should be focused on combinatorial approaches to overcome resistance against therapeutics in resistant phenotypes.

\section{Competing interests}

The authors declare that they have no competing interests.

\section{Authors' contributions}

AA conceived the idea. YCG, KB and MY searched for literature based on Rutin and checked for most relevant findings of the topic. AA, IS, AAF and SF integrated different sections of literatures and drafted the manuscript. IS, YCG, KB and MY together discussed concluding part. SF and AAF designed the diagram. All authors read and approved the final manuscript.

\section{Author details}

${ }^{1}$ Faculty of Science, Department of Biology, Division of Botany, Istanbul University, Istanbul 34460, Turkey. ${ }^{2}$ Diagnostic Imaging and Radiation Therapy Department, Lviv National Medical University, Lviv, Ukraine. ${ }^{3}$ Laboratory for Translational Oncology and Personalized Medicine, Rashid Latif Medical College, 35 Km Ferozepur Road, Lahore, Pakistan.

Received: 9 October 2014 Accepted: 7 November 2014

Published online: 30 November 2014

\section{References}

1. Alenzi FQ, Lotfy M, Wyse R: Swords of cell death: caspase activation and regulation. Asian Pac J Cancer Prev 2010, 11(2):271-280.

2. Sankari SL, Masthan KM, Babu NA, Bhattacharjee T, Elumalai M: Apoptosis in cancer-an update. Asian Pac J Cancer Prev 2012, 13(10):4873-4878.

3. Li G, Chang H, Zhai YP, Xu W: Targeted silencing of inhibitors of apoptosis proteins with siRNAs: a potential anti-cancer strategy for hepatocellular carcinoma. Asian Pac J Cancer Prev 2013, 14(9):4943-4952.

4. Ghasemzadeh A, Jaafar HZ, Rahmat A, Devarajan T. Evaluation of Bioactive Compounds, Pharmaceutical Quality, and Anticancer Activity of Curry Leaf (Murraya koenigii L.). Evid Based Complement Alternat Med. doi:10.1155/ 2014/873803.

5. Cristina Marcarini J, Ferreira Tsuboy MS, Cabral Luiz R, Regina Ribeiro L, Beatriz Hoffmann-Campo C, Ségio Mantovani M: Investigation of cytotoxic, apoptosis-inducing, genotoxic and protective effects of the flavonoid rutin in HTC hepatic cells. Exp Toxicol Pathol 2011, 63(5):459-465.

6. Dijksterhuis JP, Petersen J, Schulte G: WNT/Frizzled signalling: receptor-ligand selectivity with focus on FZD-G protein signalling and its physiological relevance: IUPHAR Review 3. Br J Pharmacol 2014, 171(5):1195-1209.

7. Reya T, Clevers H: Wnt signalling in stem cells and cancer. Nature 2005, 434(7035):843-850.

8. Bourogaa E, Bertrand J, Despeaux M, Jarraya R, Fabre N, Payrastre L, Demur C, Fournié JJ, Damak M, Feki AE, Racaud-Sultan C: Hammada scoparia flavonoids and rutin kill adherent and chemoresistant leukemic cells. Leuk Res 2011, 35(8):1093-1101.

9. Jiang Y, Zhang Y, Wark L, Ortiz E, Lim S, He H, Wang W, Medeiros D, Lin D (2011). Wolfberry Water Soluble Phytochemicals Down-Regulate ER Stress Biomarkers and Modulate Multiple Signaling Pathways Leading To Inhibition of Proliferation and Induction of Apoptosis in Jurkat Cells. J Nutr Food Sci. 2011 Nov 24;52.

10. Amado NG, Fonseca BF, Cerqueira DM, Reis AH, Simas AB, Kuster RM, Mendes FA, Abreu JG: Effects of natural compounds on Xenopus embryogenesis: a potential read out for functional drug discovery targeting Wnt/ $\beta$-catenin signaling. Curr Top Med Chem 2012, 12(19):2103-2113.

11. Choi KS, Kundu JK, Chun KS, Na HK, Surh YJ: Rutin inhibits UVB radiationinduced expression of COX-2 and iNOS in hairless mouse skin: p38 MAP kinase and JNK as potential targets. Arch Biochem Biophys 2014, 559:38-45.

12. Wang $Y X$, Cai $H$, Jiang $G$, Zhou TB, Wu H: Silibinin Inhibits Proliferation, Induces Apoptosis and Causes Cell Cycle Arrest in Human Gastric Cancer MGC803 Cells Via STAT3 Pathway Inhibition. Asian Pac J Cancer Prev 2014, 15(16):6791-6798.

13. Aneknan P, Kukongviriyapan V, Prawan A, Kongpetch S, Sripa B, Senggunprai L: Luteolin arrests cell cycling, induces apoptosis and inhibits the JAK/STAT3 pathway in human cholangiocarcinoma cells. Asian Pac J Cancer Prev 2014, 15(12):5071-5076.

14. Ge YQ, Xu XF, Yang B, Chen Z, Cheng RB: Saponins from Rubus parvifolius L. induce apoptosis in human chronic myeloid leukemia cells through AMPK activation and STAT3 inhibition. Asian Pac J Cancer Prev 2014, 15(13):5455-5461.

15. Sheng $Q$, Liu J: The therapeutic potential of targeting the EGFR family in epithelial ovarian cancer. Br J Cancer 2011, 104(8):1241-1245.

16. Huang Y, Fu P, Fan W: Novel targeted therapies to overcome trastuzumab resistance in HER2-overexpressing metastatic breast cancer. Curr Drug Targets 2013, 14(8):889-898.

17. Cheng L, Zhang S, Alexander R, Yao Y, MacLennan GT, Pan CX, Huang J, Wang M, Montironi R, Lopez-Beltran A: The landscape of EGFR pathways and personalized management of non-small-cell lung cancer. Future Oncol 2011, 7(4):519-541.

18. Choi S, Lim TG, Hwang MK, Kim YA, Kim J, Kang NJ, Jang TS, Park JS, Yeom MH, Lee KW: Rutin inhibits B[a]PDE-induced cyclooxygenase-2 expression by targeting EGFR kinase activity. Biochem Pharmacol 2013, 86(10):1468-1475.

19. Eferl R, Wagner EF: AP-1: a double-edged sword in tumorigenesis. Nat Rev Cancer 2003, 3(11):859-868.

20. Manning AM, Davis RJ: Targeting JNK for therapeutic benefit: from junk to gold? Nat Rev Drug Discov 2003, 2(7):554-565.

21. Perkins ND: Integrating cell-signalling pathways with NF-kappaB and IKK function. Nat Rev Mol Cell Biol 2007, 8(1):49-62.

22. Wang M, Kaufman RJ: The impact of the endoplasmic reticulum proteinfolding environment on cancer development. Nat Rev Cancer 2014, 14(9):581-597.

23. Gregersen N, Bross P: Protein misfolding and cellular stress: an overview. Methods Mol Biol 2010, 648:3-23.

24. Chen H, Miao Q, Geng M, Liu J, Hu Y, Tian L, Pan J, Yang Y: Anti-tumor effect of rutin on human neuroblastoma cell lines through inducing G2/ M cell cycle arrest and promoting apoptosis. Scientific World Journal 2013, 29(2013):26915.

25. Ravi A, Alvala M, Sama V, Kalle AM, Irlapati VK, Reddy BM: Anticancer activity of Pupalia lappacea on chronic myeloid leukemia K562 cells. Daru 2012, 20(1):86.

26. Okonogi S, Khonkarn R, Mankhetkorn S, Unger FM, Viernstein $\mathrm{H}$ : Antioxidant activity and cytotoxicity of Cyrtosperma johnstonii extracts on drug sensitive and resistant leukemia and small cell lung carcinoma cells. Pharm Biol 2013, 51(3):329-338.

27. Alonso-Castro AJ, Domínguez F, García-Carrancá A: Rutin exerts antitumor effects on nude mice bearing SW480 tumor. Arch Med Res 2013, 44(5):346-351.

28. Tseng HH, Chen PN, Kuo WH, Wang JW, Chu SC, Hsieh YS: Antimetastatic potentials of Phyllanthus urinaria L on A549 and Lewis lung carcinoma cells via repression of matrix-degrading proteases. Integr Cancer Ther 2012, 11(3):267-278.

29. Lin JP, Yang JS, Lin JJ, Lai KC, Lu HF, Ma CY, Sai-Chuen Wu R, Wu KC, Chueh FS, Gibson Wood W, Chung JG: Rutin inhibits human leukemia tumor growth in a murine xenograft model in vivo. Environ Toxicol 2012, 27(8):480-484.

30. Ping $X$, Junqing J, Junfeng J, Enjin J: Radioprotective effects of troxerutin against gamma irradiation in V79 cells and mice. Asian Pac J Cancer Prev 2011, 12(10):2593-2596. 
31. Feng $L$, Jia $X$, Zhu MM, Chen Y, Shi F: Antioxidant activities of total phenols of Prunella vulgaris $L$. in vitro and in tumor-bearing mice. Molecules 2010, 15(12):9145-9156.

32. Lin JP, Yang JS, Lu CC, Chiang JH, Wu CL, Lin JJ, Lin HL, Yang MD, Liu KC, Chiu TH, Chung JG: Rutin inhibits the proliferation of murine leukemia WEHI-3 cells in vivo and promotes immune response in vivo. Leuk Res 2009, 33(6):823-828.

33. Kahali B, Marquez SB, Thompson KW, Yu J, Gramling SJ, Lu L, Aponick A, Reisman D (2014). Flavonoids from each of the six structural groups reactivate BRM, a possible cofactor for the anticancer effects of flavonoids. Carcinogenesis. 2014 May 29

34. Vinothkumar R, Vinoth Kumar R, Sudha M, Viswanathan P, Balasubramanian T, Nalini N: Modulatory effect of troxerutin on biotransforming enzymes and preneoplasic lesions induced by 1,2-dimethylhydrazine in rat colon carcinogenesis. Exp Mol Pathol 2014, 96(1):15-26.

35. van der Bij GJ, Bögels M, Oosterling SJ, Kroon J, Schuckmann DT, de Vries HE, Meijer S, Beelen RH, van Egmond M: Tumor infiltrating macrophages reduce development of peritoneal colorectal carcinoma metastases. Cancer Lett 2008, 262(1):77-86.

36. Boyle SP, Dobson VL, Duthie SJ, Hinselwood DC, Kyle JA, Collins AR: Bioavailability and efficiency of rutin as an antioxidant: a human supplementation study. Eur J Clin Nutr 2000, 54(10):774-782.

37. Erlund I, Kosonen T, Alfthan G, Mäenpää J, Perttunen K, Kenraali J, Parantainen J, Aro A: Pharmacokinetics of quercetin from quercetin aglycone and rutin in healthy volunteers. Eur J Clin Pharmacol 2000, 56(8):545-553.

38. Chen IL, Tsai YJ, Huang CM, Tsai TH: Lymphatic absorption of quercetin and rutin in rat and their pharmacokinetics in systemic plasma. J Agric Food Chem 2010, 58(1):546-551.

39. Rastogi H, Jana S: Evaluation of physicochemical properties and intestinal permeability of six dietary polyphenols in human intestinal colon adenocarcinoma Caco-2 cells. Eur J Drug Metab Pharmacokinet, 2014 Oct 29

40. Nguyen TA, Liu B, Zhao J, Thomas DS, Hook JM: An investigation into the supramolecular structure, solubility, stability and antioxidant activity of rutin/cyclodextrin inclusion complex. Food Chem 2013, 136(1):186-192.

41. Sri KV, Kondaiah A, Ratna JV, Annapurna A: Preparation and characterization of quercetin and rutin cyclodextri $\mathrm{n}$ inclusion complexes. Drug Dev Ind Pharm 2007, 33(3):245-253.

42. Lauro MR, Torre ML, Maggi L, De Simone F, Conte U, Aquino RP: Fast- and slow-release tablets for oral administration of flavonoids: rutin and quercetin. Drug Dev Ind Pharm 2002, 28(4):371-379.

43. de Araújo ME, Moreira Franco YE, Alberto TG, Sobreiro MA, Conrado MA, Priolli DG, Frankland Sawaya AC, Ruiz AL, de Carvalho JE, de Oliveira Carvalho P: Enzymatic de-glycosylation of rutin improves its antioxidant and antiproliferative activities. Food Chem 2013, 141(1):266-273.

44. Mladenović M, Matić S, Stanić S, Solujić S, Mihailović V, Stanković N, Katanić J: Combining molecular docking and 3-D pharmacophore generation to enclose the in vivo antigenotoxic activity of naturally occurring aromatic compounds: myricetin, quercetin, rutin, and rosmarinic acid. Biochem Pharmacol 2013, 86(9):1376-1396.

45. Barcelos GR, Grotto D, Angeli JP, Serpeloni JM, Rocha BA, Bastos JK, Barbosa F Jr: Evaluation of Antigenotoxic Effects of Plant Flavonoids Quercetin and Rutin on HepG2 Cells. Phytother Res 2011, 25(9):1381-1388.

46. Maeda J, Roybal EJ, Brents CA, Uesaka M, Aizawa Y, Kato TA: Natural and glucosyl flavonoids inhibit poly(ADP-ribose) polymerase activity and induce synthetic lethality in BRCA mutant cells. Oncol Rep 2014, 31(2):551-556.

doi:10.1186/s12935-014-0124-6

Cite this article as: Perk et al:: Rutin mediated targeting of signaling machinery in cancer cells. Cancer Cell International 2014 14:124.

\section{Submit your next manuscript to BioMed Central and take full advantage of:}

- Convenient online submission

- Thorough peer review

- No space constraints or color figure charges

- Immediate publication on acceptance

- Inclusion in PubMed, CAS, Scopus and Google Scholar

- Research which is freely available for redistribution

Submit your manuscript at www.biomedcentral.com/submit 